\title{
Documentación
}

\section{El Instituto de Investigaciones Económicas y Sociales (IIES-UCA)}

Cada vez más nuestra realidad compleja y multiforme lanza un reto a todos los profesionales de las Ciencias Sociales. Nuestra realidad son las personas, la vida de las personas en sociedad. Tenemos un peligro cientifico: transformar a las personas en cifras, en variable macroeconómicas, y luego nos dedicamos a jugar mecánicamente con esos grandes agregados, preanunciando un futuro de estabilidad y de recuperación. Se crean modelos económicos o más bien se importan, a modo de las antiguas armaduras medievales y pedimos a nuestra gente que se acomode al peso y a la forma de la moldura; se les dice que su mayor seguridad está dentro de ese ajuste estructural. Se ajusta a los que siempre han estado ajustados, y desde el interior de la coraza nos interrogan si no habrá otras técnicas más humanas para hacer la guerra a la pobreza, al desempleo, a la desequilibrada distribución del crecimiento y del desarrollo.

Por esta razón en el Departamento de Economía de la UCA creíamos un derecho-deber liberar a nuestros profesores de la tradicional carga docente interna y dedicar sus mejores potencialidades a ordenar, armonizar y proponer hacia fuera nuevas modalidades y alternativas no prefabricadas por un partidismo político o por un apriori ideológico. No puede darse una solución que prescinda de la realidad social por el simple principio de que el modelo está de moda. $Y$ algo de esto le sucede al modelo que nos han impuesto, que aunque reciba el visto bueno de los de fuera no se han ganado el parabien de los de dentro. Sencillamente, no es un modelo democrático y el pueblo no se ajusta a 
la moldura.

Para expresarlo en terminologla más entendible y hacer la introducción al Plan de Investigación del IIES-UCA, afimamos que en EI Salvador el desarrollo económico se basa en dos principios fundamentales: 1) Un crecimiento económico fuerte y sostenido, acompanado de niveles elevados de empleo; 2) una distribución más equitativa del ingreso y de los frutos del crecimiento... También es evidente que entre los objetivos de un crecimiento económico fuerte y de una distribución más equitativa de los f́utos del mismo, pueden presentarse conflictos. Las estrategias de desarrollo o los "proyectos de nación" se diferencian fundamentalmente por la forma en que revuelven o plantean resolver esos conflictos.

Lo que aqul se presenta son unos lineamientos razonables del plan de investigación, marcando, al mismo tiempo, la complejidad, las alternativas y las consecuencias previsibles de to que puede anallzarse y realizarse en el más corto y en el mediano plazo. Es un plan de trabajo para el Instituto, abierto a cuantos deseen colaborar con sus sugerencias y observaciones, o para quienes buscan áreas concretas de investigación personal. Es un plan de investigación con óptica democrática, al servicio de las mayorlas populares. 